\title{
Division of Cancer Epidemiology and Genetics
}

National Cancer Institute

\section{Source}

National Cancer Institute. Division of Cancer Epidemiology and Genetics. NCI Thesaurus. Code C18749.

The Division of Cancer Epidemiology and Genetics (DCEG) is the primary focus within the National Cancer Institute for population based research on environmental and genetics determinants of cancer. Intramural and collaborative interdisciplinary studies are conducted on the distribution, causes, and natural history of cancer, and the means for its prevention. Research areas of special interest include genetic predisposition, lifestyle factors, environmental contaminants, occupational exposures, medications, radiation and infectious agents, as well as statistics and methods development. 